Prof. Hele Shaw, of Liverpool, has been appointed senior professor, and he will be in charge of the department of mechanical and electrical engineering, with Prof. Orr, late of Kimberley, as assistant professor. The chair of mining engineering and the assistantship in that department have not yet been filled, but arrangements will soon be completed for the due carrying on of this department.

The courses at present provided by the Transvaal Technical Institute are those of the third and fourth years of the Cape mining curriculum arranged by the University of the Cape of Good Hope, but the council has under consideration the development of the Institute, so as not only to give a complete four years' mining course, but also to provide courses in other departments of engineering and technical education generally, and to provide post-graduate courses for mining engineers.

Evening classes in subjects bearing on certain trades and industries are already being carried on in Pretoria and in Johannesburg, and the council is preparing a scheme of technical instruction for mines employees and others which involves the early opening of evening and day classes along the line of Reef, and eventually in other parts of the Transvaal.

The council of the Institute has also under consideration the wider proposals recommended by the Commission on Technical Education, and it is intended that no undue delay shall intervene in the carrying out of these.

John RoBinson (Secretary).

Transvaal Technical Institute, Secretary's Office, Johannesburg, December 23, 1903.

\section{The Quadrantid Meteor Shower of Ig04.}

THE evenings of January 2 and 3 were clear here, but the moon being full and near perigee, rendered invisible in the north-eastern sky all stars less bright than second magnitude. A brief watch before midnight on January 2 indicated a total absence of meteors, and it was not thought advisable to prolong observations on this night, as it had been previously determined by the writer that it was on the following night that the Quadrantid maximum would occur.

The calculated time of this maximum was January 3 I8h. G.M.T. On the same night there was an earlier, and what had been supposed would be a much weaker, maximum at $13 \mathrm{~h}$. Observations were therefore commenced here shortly after midnight, and it very soon became apparent that, notwithstanding the strong moonlight, shooting stars were unusually numerous. Between $12 \mathrm{~h} .5 \mathrm{~m}$. and $13 \mathrm{~h}$. (Dublin time) there were observed 17 meteors, of which 8 were as bright, or brighter, than first magnitude stars. They made their appearance at very considerable distances from the Quadrantid radiant, and, owing to the very limited number of fixed stars visible in that quarter of the sky, it was impossible to record the meteor-paths with accuracy, but several of the latter indicated a divergence from the region of Boötes, there being at the same time another probable centre of emanation near the tail stars of Ursa Major.

The advent of clouds from the south-east rendered observations impracticable or fruitless between $13 \mathrm{~h}$. and $14 \mathrm{~h}$. $15 \mathrm{~m}$., but during the first quarter of an hour succeeding this interruption 4 more meteors were seen, of which 2 were of first and the rest of second stellar magnitude. The early maximum of the night was now evidently declining, as in the next half hour but 3 shooting stars were visible, the two brightest of these being only of second magnitude. The two hours' interval between $15 \mathrm{~h}$. and $\mathrm{r} 7 \mathrm{~h}$. was remarkable for its meteoric paucity, only I bright meteor equal to second magnitude having been observed during this period at ${ }_{15} \mathrm{~h}$. $30 \mathrm{~m}$., though the sky was very clear; and the watch would very probably have been abandoned after I5h. but for the maximum expected some hours later. This anticipation of a recrudescence of the phenomenon was fully realised, for between $17 \mathrm{~h}$. and $\mathrm{I} 7 \mathrm{~h}$. 3om. ro meteors were observed (half of them of first magnitude), although twothirds of the eastern sky had by this time become covered with light clouds. The meteors radiated in all directions from a region very evidently situated in the north of Boötes. In the next ten minutes 2 more Quadrantids were observed, No. 1786 , vor. 69 ] although the clouded area had by this time increased to fivesixths. Observations were discontinued at $17 \mathrm{~h}$. $4 \mathrm{om}$. The meteors had a fairly rapid motion, and were slightly red in colour. Their paths ranged from $10^{\circ}$ to $20^{\circ}$ in length. The excessive moonlight must have detracted considerably from the splendour of the present display, but, even as it was, the meteoric rate during the shower's activity was much higher on the night of January 3 than on the corresponding night in 1903 .

Dublin, January 13.

JOHN R. HENRY.

\section{Blondlot's $n$-Ray Experiments.}

IT would be interesting to know whether anyone has succeeded in confirming the above, as described in your columns and elsewhere.

Personally, I have repeated most of M. Blondlot's experiments, but $I$ have not been able to discern the slightest trace of any of the remarkable phenomena that he describes. This is also, the case with Mr. J. C. M. Stanton and Mr. R. C. Pierce, who have assisted me in the investigations.

In order to get away from personal physiological idiosyncrasies we have also applied delicate photographic methods of observation, but without result, and as a general conclusion I am inclined to think that M. Blondlot's observations must be due, not to physical, but to physiological processes, and further, that these are not operative in the case of all persons.

Perhaps others may have tried the experiments and may have met with greater success.

A. A. Campbell Swinton.

66 Victoria Street, London, S.W., January 19.

\section{Phosphorescence of Photographic Plates.}

Some time ago when developing an X-ray photograph I observed the effect noticed by your correspondent in your last issue. Very little of the silver salt had been affected, and the plate, after development, when put into alum solution lit up as described. I have often watched for the same effect since with ordinary negatives; sometimes there is phosphorescence, sometimes not. Apparently a fairly long development with the pyro soda is necessary. Not only the plate itself, but the used developer will give the phosphorescence with alum solution. Dilute sulphuric acid may be used instead of the alum. Quinine sulphate or hydrochloride does not light up when the used developer is added, but will do so if a few drops of sulphuric acid are subsequently introduced. Printing out paper may sometimes be successfully used instead of the plate, or the experiment may be still more easily made by mixing potassium bromide and silver nitrate solutions in dim gaslight, decanting, and shaking up the resulting silver bromide with pyro soda. A red liquid results which gives the lighting up effect when poured into alum solution or dilute sulphuric acid.

Heaton, Newcastle-on-Tyne, January i6. H. J. EDWARDS.

\section{BIRD-LIFE IN WALES. 1}

A LTHOUGH the writings of Messrs. Murray I Mathew, Cambridge Phillips and others have made us more familiar with the avifauna of southern Wales than we are with that of some other parts of that country, Mr. Walpole-Bond's description of the bird-life of a part of the district is not any the less welcome and instructive. For he enters very fully into the nesting habits and comparative abundance or scarcity of the birds in a way that is only possible to a good climber, indifferent to weather, who is able to devote every day wholly to the pursuit of his favourite study. The wild Wales of this book seems to lie, in the main, in part of the county of Brecon, although Pembrokeshire and other districts are touched upon. Incidentally, Bucks, Kent, and Hampshire are mentioned.

1 "Bird Life in Wild Wales." By J. A. Walpole-Bond. Illustrated with photographs by Oliver G. Pike. Pp. xv+283. (London: T. Fisher Unwin, 19०3.) Price 7s. 6d. 